\title{
Integrity Inspection of a Steam Turbine Rotor in a Geothermal Power Plant
}

\author{
M. Nurbanasari \\ Department of Mechanical Engineering \\ Institut Teknologi Nasional \\ Bandung, Indonesia
}

\begin{abstract}
A 55 MW steam turbine in geothermal generation power plant has been in service for 26 years. This turbine stopped working in $\mathbf{2 0 1 3}$ due to the failure of a first stage blade. By considering the damage and maintenance works are important for geothermal turbine to maintain the reliable operation before it will be back in use, the integrity inspection must be conducted. The methodology for integrity inspection was nondestructive tests e.g.; visual inspection, dye penetrant, UT phased array, eddy current, hardness, chemical composition test and microstructure analysis using replica technique. Chemical composition analysis, hardness data and microstructure analysis gave evidence that the material rotor met the standard of ASTM A470 class 8.Visual inspection and dye penetrant found that there were some surface defects and microstructure analysis on replica showed that pitting was observed. However, UT phased array and radiograph results revealed that no internal defects were found, which indicated that the surface defects only occurred on the surface and pitting did not propagate. Results of eddy current inspection proved there were no fine cracks on all areas. From the inspection results, it can be summarized that at the present, the steam turbine rotor is in good condition and safely returned to service after minor repair.
\end{abstract} defects

Keywords-rotor shaft; integrity inspection; non-destructive test;

\section{INTRODUCTION}

A steam turbine in power plant is one of major components to generate electrical power. This component is designed for prolonged service time. Jonas and Macheme [1] reported that steam turbine can be operated for more than 30 years with a downtime every 10 years. However, the operation and environmental condition play important roles to decrease the lifetime of the component or to cause premature failure. In geothermal steam turbine, the main problems due to the usage of working fluid are scaling, erosion and corrosion [2, 3]. The erosion occurred because solid particles or water droplets hit the surface of components. The corrosion environments were formed by the phase changes from steam to water of the working fluid and the impurities were brought by the steam, such as steam, moisture, liquid films, and deposits [1]. The type and properties of component's materials, the chemical composition of steam, working temperature and the relative velocity of the steam are some factors, which affect the level of damage on the components. This paper reported the integrity inspection to evaluate the condition of a $55 \mathrm{MW}$ geothermal steam turbine rotor. The turbine has been operated for 26 years old and last inspection was carried out about ten years ago. Historical damage noted that the turbine had stopped working in 2013 due to corrosion fatigue of a first stage blade [4]. By considering the historical damage and maintenance works, inspection of turbine rotor is a great concern to be carried out to confirm the integrity of the material rotor shaft at present situation before it will be back in service. The condition assessment of turbine rotor is also important for safety, reliability and economic assessment [5]. It is noteworthy that as for geothermal turbine, the working temperature is below $200 \mathrm{oC}$, the consumption life due to creep will not appear in the geothermal turbine. However erosion and corrosion were the dominant factors for material degradation. Figure. 1 shows the inspected steam turbine rotor. The condition of turbine rotor (see Figure. 1) to be inspected was the first and second stages of disc in both generator and governor sides without blades as well as the third stage in generator side. The others stages of disc in generator and governor sides are with attached blades.

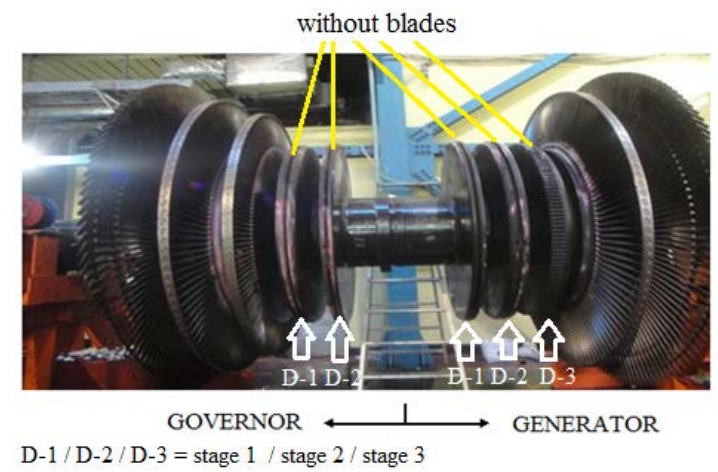

FIGURE I. INSPECTED STEAM TURBINE ROTOR.

Figure 1 shows the typical rotor shaft of geothermal steam turbine to be inspected. The turbine contains 5 stages on generator and governor sides, respectively and operates at 161.9 oC and 6.82 bar.

\section{METHODOLOGY}

The methods used in this work for monitoring condition of the turbine rotor consisted of visual inspections, dye penetrant, UT phased array, Eddy current and metallography using replica technique. Dye penetrant used remover SKC S1, penetrant SKL SP and developer SKD S2 following the standard of ASME E165. Penetrating, emulsifying and developing times were 10 minutes, respectively. UT phased array (Olympus) was performed to find internal defects. Eddy current was also conducted using Weld Check product Ether 
NDE UK to detect fine defects on the surface and sub-surface. Calibration was needed for UT phased array and eddy current before doing the inspections. As the turbine had stopped operating due a crack of a first stage blade, the radiograph inspection was conducted on disc of stage 1 at governor and generator sides. The radiograph camera used sentinel 880 and type of source was Ir-192. The type of film was AGFA D7. Material turbine was verified based on chemical composition, hardness and microstructure. Chemical composition test used master pro-oxford instrument (positive material identification method) with a standard of ASTM E415 - 08. Hardness test was measured using Vickers method with a 200 grams load. A standard metallography of replica was done and an etchant of $5 \%$ nital was used to reveal the microstructure.

\section{Results AND Discussions}

The chemical composition test of material rotor was presented in Table 1.

TABLE I . CHEMICAL COMPOSITION OF MATERIAL ROTOR AND ASTM A 470 (WT\%)

\begin{tabular}{|c|c|c|c|c|c|c|c|c|}
\hline & $\mathbf{C}$ & $\mathbf{S i}$ & $\mathbf{M n}$ & $\mathbf{C r}$ & $\mathbf{M o}$ & $\mathbf{N i}$ & $\mathbf{V}$ & $\mathbf{F e}$ \\
\hline Result & 0.27 & 0.12 & 0.56 & 0.93 & 0.74 & 0.37 & 0.15 & balance \\
\hline $\begin{array}{c}\text { ASTM } \\
\text { A470 }\end{array}$ & $\begin{array}{c}0.25- \\
0.35\end{array}$ & $\begin{array}{c}0.15- \\
0.35\end{array}$ & $\begin{array}{c}\leq \\
1.0\end{array}$ & $\begin{array}{c}0.9- \\
1.5\end{array}$ & $\begin{array}{c}1.0- \\
1.5\end{array}$ & $\begin{array}{c}\leq \\
0.75\end{array}$ & $\begin{array}{c}0.20- \\
0.30\end{array}$ & balance \\
\hline
\end{tabular}

From the data in Table 1, it can be seen that the type of material rotor is $\mathrm{CrMoV}$ alloy steel. The hardness value of the material rotor was $256.2 \mathrm{HV}$ and the microstructure of rotor material is shown in Figure. 2.

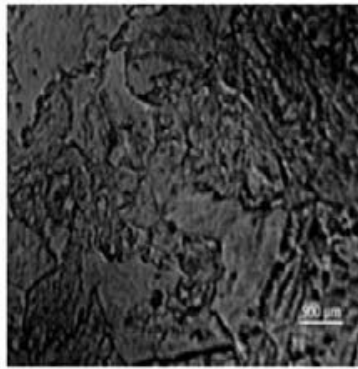

(a) baimitic structure

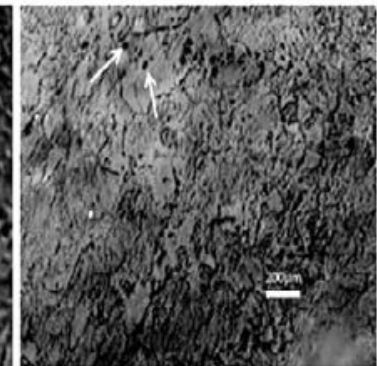

(b) pitting on the microstructure (indicated by anrows)
FIGURE II. MICROSTRUCTURE OF ROTOR MATERIAL (A) AND PITTING WAS OBSERVED (B).

Microstructure of the rotor material using replica technique shows that the material rotor has a bainitic structure (Figure.2a) and there is no indication that the material had experienced phase changes and exposed to high temperature. The bainitic structure supported the evidence that the type of material rotor is CrMoV steel alloy. Based on chemical composition, hardness data and microstructure analysis, it can be concluded that the material rotor satisfied with the ASTM A470 class 8 . Microstructure analysis shows that pitting had occurred (Figure. 2b). The depth of pitting would be clarified using UT phased array. Visual inspection and dye penetrant method found some defects, as can be seen in Figures. 3 and 4.

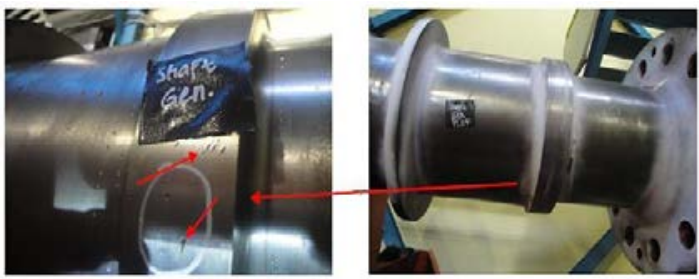

(a) notch on generator shaft before dye penetrant (left) and after dye penetrant (right).

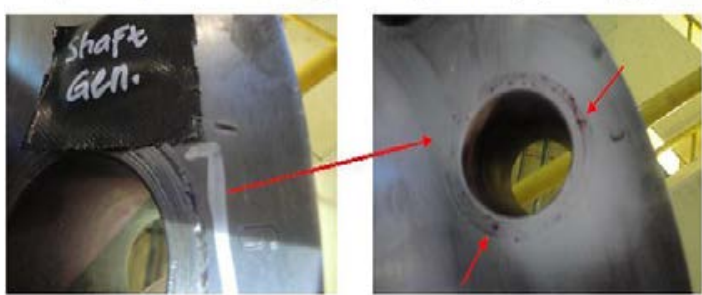

(a) scratch on generator shaft before dye penetrant (left) and after dye penetrant (right).

FIGURE III. NOTCH AND SCRATCH (INDICATED BY ARROWS) ON GENERATOR SHAFT.

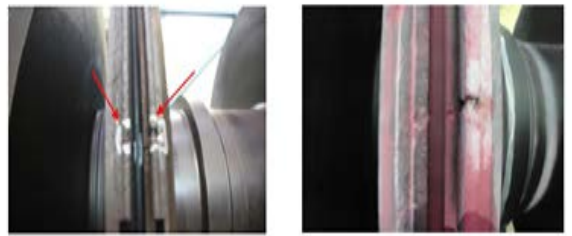

(a) notch found near to pinlock on governor side before dye pentrant (left) and after dye penertrant (right).

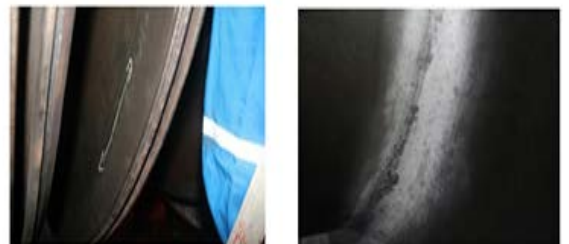

(b) scratch at the first stage on generator side before dye penetrant (left) and affer dye penetrant (right).

FIGURE IV. DEFECTS ON GOVERNOR AND GENERATOR SIDES (INDICATED BY ARROWS).

Figures.3 and 4 show some surface defects (notch and scratch) that were found from visual inspection and dye penetrant. Notch that was observed near to pin lock on governor side (Figure.4a) seems due to mechanical collision when the blade was released. UT phased array and eddy current were conducted on all areas, and special attention was given to the area with surface defect sand pitting. The results of eddy current inspection in all areas indicated that no fine cracks either in surface or sub surface were detected and the results of UT phased array show that there were no internal defects. Therefore, it can be concluded that the notch, scratch and pitting occurred only on the surface and no evidence that pitting had propagated. The result of UT phased array on one of surface defect area (Figure. 4b) can be seen in Figure. 5. 


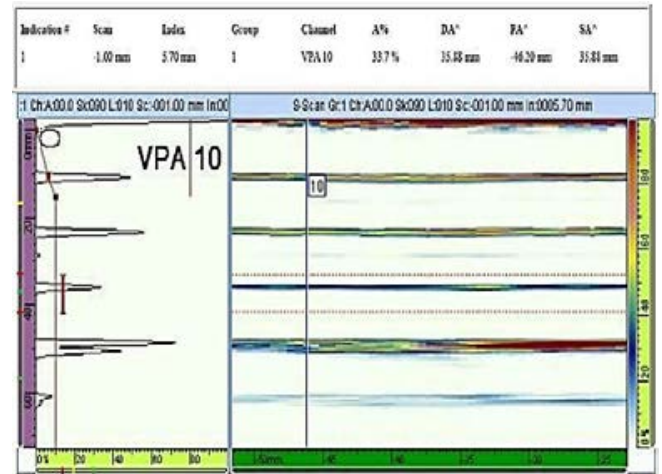

FIGURE V. UT PHASED ARRAY RESULT SHOWS NO DEFECT'S REFLECTOR ON SCANNED AREA.

As the turbine had stopped working due to failure of a first stage blade, radiography inspection was conducted on disc of stage 1 at governor and generator sides to get more accurately results for evaluation. The film location on disc can be seen in Figure. 6.

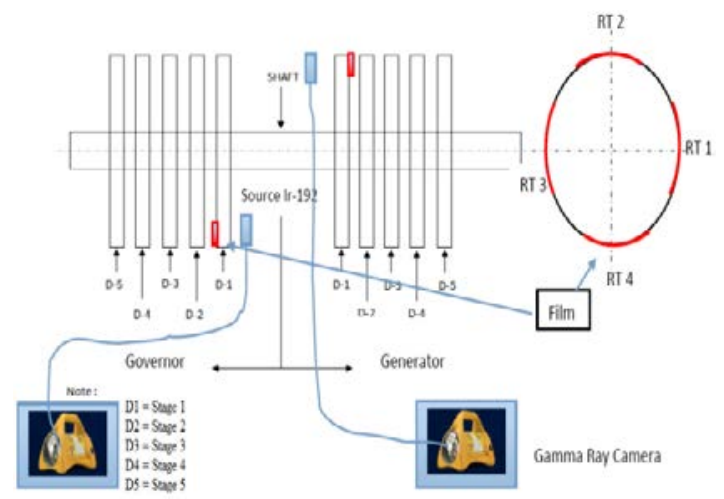

FIGURE VI. INSPECTED AREA AND FILM LOCATION IN RADIOGRAPH INSPECTION.

The RT 1 was the most critical area for blade attachment namely at pin lock of stage 1 looked at from governor side. The film was located in three different areas namely RT2, RT 3 and RT4 with counter clock wise direction (see Figure. 6). The results of radiograph inspection show that there were no internal defects.

\section{CONCLUSIONS}

Based on chemical composition analysis, hardness data and microstructure analysis on replica, the material rotor was a typical Cr-Mo-V steel and satisfied with the ASTM A 470 class 8 . Some surface defects were observed with visual inspection and dye penetrant, such as notch, scratch and pitting. However, intensive inspections using UT phased array and eddy current showed that there were no internal and fine defects and no indication the defects had propagated. Hence, at the present, the rotor shaft is safely returned to continued reliable operation after undergoing minor repair.

\section{REFERENCES}

[1] Jonas, L. Machemer,Steam turbine corrosion and deposits problems and solutions, in: Proceedings of the thirty-seventh turbomachinery symposium, Turbomachinery Laboratory, Houston, Texas, 2008.
[2] R.S. Atlason, A. Gunnarsson, R. Unnthorsson, Turbine repair at Nesjavellir geothermal power plant: An Icelandic case study, Geothermics 53 (2015) 166-170.

[3] B. Staniša, V. Ivušić, Erosion behavior and mechanisms for steam turbine rotor blades, Wear, 186-187, Part 2 (1995) 395-400.

[4] M. Nurbanasari, Abdurrachim, Crack of a first stage blade in a steam turbine, Case Studies in Eng. Fail. Anal., 2 (2014) 54-60.

[5] L. Chongsheng, B. Jianwei, Condition Assessment of A 360MW Turbine, in: Int. Conference on Mechanical Engineering and Material Science, Atlantis Press, Yangzhou, China, 2012, pp. 269-272. 